\title{
New Vegetarianism: Food, Gender and Neo-Liberal Regimes in Bengali Middle-Class Families ${ }^{1}$
}

\author{
Henrike Donner \\ London School of Economics and Political Science
}

\section{Introduction}

In the 1990s, as the lifestyle of the Indian middle classes underwent dramatic change, an emerging consumerist orientation challenged many of the certainties embedded in everyday practices. Amongst the arenas where these changes were played out, food consumption and the availability of new foods across India's metropolitan areas were particularly prominent, but have been notably absent in the analysis of these new lifestyles. That changing food habits signify wider social transformations in the aftermath of neo-liberal reform has been documented in some detail in the case of other regions, e.g. China, ${ }^{2}$ but in spite of a rich literature on traditional understandings of food and food practices in South Asia there has been little interest in the way such important everyday activities as eating at home or in public, snacking and feasting have been transformed in contemporary India. ${ }^{3}$ Furthermore, where consumption has been identified as a hallmark of new middle-class lifestyles it has been largely viewed in terms of the 'public modernity' paradigm. Thus the focus of social scientists has been on the public sphere, i.e. the emerging youth

\footnotetext{
${ }^{1}$ The fieldwork on which this article is based was conducted between 1995 and 2005 and the research was supported by the ESRC. Earlier versions of this article were presented at SOAS, the University of Oslo and the LSE and I am grateful to all participants for useful suggestions.

${ }^{2}$ Jun Jing (ed.), Feeding China's Little Emperors: Food, Children and Social Change (Stanford: Stanford University Press, 2000).

${ }^{3}$ Pat Caplan, 'Food in Middle-Class Madras Households from the 1970s to 1990s', in Katarzyna Cwiertka and Boudewijn C.A. Walraven (eds), Asian Food: The Global and the Local (Richmond: Curzon, 2002), pp. $46-62$.
} 
cultures, fashion and advertising. ${ }^{4}$ This take on consumption has not only directed our attention away from the family and the household as important sites of consumption practices, but has also introduced a bias whereby the new middle-class lifestyles are defined in terms of youthful, and often largely male, public cultures, while women's involvement in, and resistance to, such new practices is analysed in terms of media images and the role of (mostly young) women as consumers in public places. While a wide range of significant changes have no doubt led to new forms of middle-class consumption to which women increasingly have access, it is also true that the household as a major site of consumption and resistance to such emerging regimes has been marginalised in this analytical discourse.

The objective of this article is to draw attention to the household as a site - in many ways the most significant site - of middle-class socialisation, consumption and lifestyles through an analysis of contemporary practices of, and ideas about, middle-class food consumption and vegetarianism in urban Bengal. Furthermore, I explore these transformations in the context of new class formations and gendered subjectivities in the context of post-liberalisation India.

For the Bengali middle class in Calcutta, the 1990s were a period of rapid transformation, and among the prime sites for these changes was the middleclass home. Although the new, more consumerist middle-class lifestyle has perhaps not yet eroded older practices in Bengali middle-class families as noticeably as in other Indian metropoles, food and its consumption-which plays such an important role in the lives of Bengali families - represents a prime site of struggles over meaning and new patterns. While Calcutttans are still a long way from the complete transformation of eating taking place elsewheresee for instance Caplan's observation in this issue that elderly parents in Chennai are receiving meals-on-wheels in the absence of children to look after their needs - a number of subtle changes and shifts can be observed.

In the course of my fieldwork following the economic reforms of the 1990s I witnessed the way new commodities and consumption patterns challenged existing notions of appropriate diets in Bengali middle-class households and I

\footnotetext{
${ }^{4}$ Two recent examples are Mark Liechty, Suitably Modern: Making Middle-Class Culture in a New Consumer Society (Princeton: Princeton University Press, 2003); and William Mazzarella, Shovelling Smoke: Advertising and Globalization in Contemporary India (Durham: Duke University Press, 2003). An earlier example is Frank F. Conlon, 'Dining Out in Bombay', in Carol A. Breckenridge (ed.), Consuming Modernity: Public Culture in a South Asian World (Minneapolis: University of Minnesota Press, 1995), pp.90-127, which focuses on the pre-liberalisation period.
} 
explored how discourses surrounding a wide range of new food practices were gendered. While women as nurturers and 'producers' of food are often at the centre of debates about food in middle-class households, their role as 'chief consumers', or non-consumers of specific kinds of food is not acknowledged to the same degree. In this article I therefore focus specifically on the multiple meanings of women's vegetarianism as a gendered food practice in Bengali middle-class families, where this kind of preference used to be the sole preserve of widows. Based on my observation that more and more young mothers are becoming vegetarians, I highlight how traditional notions of chastity and selfdiscipline associated with this practice are mobilised to adjust to and to criticise the new consumption patterns and regimes in the home, and how new vegetarianism regulates reproduction, which aims at the creation of the perfect middle-class family with a single male child, by disciplining the maternal body.

As a physical practice vegetarianism is closely linked to gendered ideologies of constraint and asceticism at the heart of which lie the need to control one's sexuality. It is this control of sexuality which gives vegetarianism its political potential and its gendered meanings: in the case of women, it is closely related to social control, as it is linked with the prevention of adultery and illegitimate offspring, i.e. in the imposed vegetarianism of widows; but in the case of men, its liberating capacities are emphasised in the figure of the renouncer. In both cases, South Asian systems of knowledge highlight vegetarianism as a means to curb sexual appetites. But whereas abstinence from food has been interpreted as a technique of the self (in the Foucauldian sense) in the West, Joseph Alter has convincingly argued with reference to Hindu North India that vegetarianism and related ideologies of celibacy constitute a 'somatic truth'. ${ }^{5}$ I would like to take this notion of a somatic truth further, and explore the gendered meanings the practices subsumed under the heading of 'vegetarianism' have for women in a contemporary setting, where the reproductive body, though increasingly medicalised, remains a site of other truths nevertheless. Taking 'new vegetarianism' seriously, the article highlights a modern understanding of this 'traditional' practice both with reference to gender, and with reference to new, class-based consumption patterns. These, as others have argued, include practices related to the body such as hygiene and cosmetics, fashion and sports, and also eating, which situate vegetarianism within a wider field of social change. How the economic reforms and the spectre of unfolding middle-class consumerism have brought about new understandings of what it means to be middle class and female, what chastity does in the context of medicalised female

\footnotetext{
${ }^{5}$ See Joseph S. Alter, 'Seminal Truth: A Modern Science of Male Celibacy in North India', in Medical Anthropological Quarterly, Vol.11, no.3 (1997), pp.275-98.
} 
bodies, and what the persons so disciplined contribute to the prime site of 'middle class-ness', the home of the single-male-child family, constitute the central concerns of this article.

\section{Local Understandings of Vegetarianism}

While writing this section I re-visited my first encounter with notions of vegetarianism living with Bengali friends of my family for three months in 1986. Theirs is a well-educated, affluent family, occupying a beautiful three-storey house in South Calcutta. There, three of six brothers had established their own households, and the house had been divided into flats with separate kitchens. The 1980s were a period of relative calm and subdued optimism in Calcutta; the Communist Party (Marxist) had just come to power and the rural areas were undergoing rapid political transformation, but the city remained in economic decline.

In the aftermath of Independence, employment in the government sector had become the most desired job among the Bengali middle class, whose lifestyle depended on these relatively secure, but moderately-paid, public jobs; the vast majority of women, meanwhile, remained housewives. In this my host's paternal family was no exception. But because all its members had been educated abroad the family was unusually cosmopolitan and much more affluent than the average middle-class household. However, although the family was very well-off, its lifestyle was not extravagant - certainly not in the eyes of a West German student - indeed it appeared to me almost austere, with a distinct GDR-like flavour due to the unavailability of certain goods and the problems with supplies of everyday items like milk and bread.

In the huge multi-storey house the wider family occupied, the preparation of food dominated many conversations, relationships and schedules. Shopping for food, and cooking and eating everyday meals was a major preoccupation in which the women and men as well as the servants were involved on a daily basis. Consequently, food and eating became one of the main vehicles through which various family members started to teach me about 'Bengali culture', and food practices contributed a great deal to what I learned about cultural differences during that first trip to India.

This, as a visiting friend pointed out, was a family of 'serious' eaters in the sense that Brahmins - especially Tamil ones with their strict vegetarianism-are considered in Bengal to be sincere about food. Thus, although a lot of pleasure was involved in their consumption, home-cooked meals were never taken 
casually or discussed in a light spirit. And although caste was never mentioned in other than ritual contexts, their food 'habits' marked the family out as highcaste. Among them was a strict differentiation between what was seen as a 'traditional' home-based vegetarian diet that included fish, but did not allow the consumption of chicken or any other meat in the house, and dietary practices outside, where most family members consumed chicken or meat. This puzzled me initially, but I was told that although Bengalis did eat fish this was 'by and large' a vegetarian household 'except for fish', and I did not question the notion of fish being a vegetarian item at the time because it was obvious that vegetarianism had not so much to do with any notion of animal protection or non-violent foods, but the idea that meat, and in particular chicken, was 'dirty' and 'polluting'. None of the younger members of the wider family was a 'full' vegetarian, but they could not consume meat inside the house because the oldest member of the family, the ageing mother of all the brothers who lived with her youngest son's family, was a widow and therefore a strict vegetarian who excluded fish, meat, onions, and masur dal from her diet. Now in her seventies, she had lost her much-older husband in her forties after giving birth to eleven children. Although she mostly sat on the veranda in a torn sari and did not speak much, she commanded the respect of her sons' daughters-in-law and was rumoured to have been an extremely strict and rather unpleasant mother-in-law in her time.

Following prevailing expectations, she proved her high-caste status through a strict adherence to tradition and insisted on cooking her own food in a separate space next to the upstairs kitchen. But to my surprise, while she seemed to accept all the 'traditional' rules governing her life, she was very tolerant towards the consumption of fish and meat by her sons and their families, and did occasionally cook specific non-vegetarian dishes for them 'with her own hands'. Indeed, this lenience towards her sons' 'modern habits' was in the view of her family members a sign of motherly devotion and of her virtuous and self-sacrificing fulfilment of this idealised role. Everybody else in the family ate fish on a daily basis and occasionally treats consisting of Chinese chicken preparations were cooked, while some of the male household members boasted of consuming beef and pork dishes in restaurants, which is crucial for exclusively-male sociality and is accompanied by alcohol.

This kind of 'selective' vegetarianism, which allowed the consumption of huge amounts of fish, and the occasional meat dish outside, was presented to me as typically 'Bengali', and is still commonly cited as proof of the assumption that in Calcutta's Bengali and Hindu middle-class culture vegetarianism is not so 
much a marker of caste but a matter of choice, an individual symbol of marital status, and an indigenous practice associated with a healthy lifestyle.

It appears therefore that vegetarianism works here as a marker, rather than as an overall constituent, of high-caste status: members of a high-caste middleclass family may not cook or consume specific kinds of meat in the house, but are only required to be strictly vegetarian on the occasion of life-cycle festivals and pujas. Conversely, members of influential sects like the Vaishnabs, who are fully vegetarian and do not eat fish, are not usually considered to be of superior ritual status. While distinctions between diets, namely an amish (meat, nonvegetarian) diet and a niramish (excluding fish, onion, meat, eggs) diet are as clear-cut in Bengal as elsewhere, these descriptive terms do not translate into vegetarian and non-vegetarian castes as such but, I would argue, into gendered persons.

Amongst the different Hindu castes of Bengal niramish food is reserved for strict vegetarians and is known as the 'diet of widows'. Widows have to avoid amish or non-vegetarian items in their diet since by convention their sexually active life ended with the death of the husband. Thus, widows do not consume 'hot' foods including meat, which are thought to enhance sexual appetite. And since fish and meat are also high-status foods in middle-class households, even today widows are expected to express in public their new role as dependents by sacrificing such expensive and potent tastes. In other words vegetarianism, through its association with widows, is related to deprivation and subordination, as from a strictly structuralist point of view the diet of widows is the opposite of the refined cuisine the male householder and his inner circle can enjoy. Though some writers point out that the ingenuity of generations of widows has contrived some of the most delicious and elaborate vegetable dishes cooked in Bengali homes, these are nevertheless cheap versions of much richer and higher-status dishes. ${ }^{6}$ With vegetarianism being not so much a simple marker of caste, but of gender, caste and marital status, it is not surprising that strict vegetarianism was previously rarely depicted as a desirable mainstream choice for married women and men, whose reproductive lives are not yet over.

For men, eating fish and, more prominently, meat, are naturalised virile practices. As long as the latter is consumed in moderation, it is considered a particular trait of male sociality. Yet while young men, especially students and

\footnotetext{
${ }^{6}$ See Rukmini Bhaya Nair, 'Are We What We Eat?', in Seminar, Vol.545 (January 2005) [http://www.indiaseminar.com/semframe.html, accessed 29 Nov. 2007].
} 
businessmen, regularly consume meat and alcohol outside the home, those fashioning themselves as true householders-good husbands and fathersrarely admit to such an indulgence as it does not really tally well with the image of middle-class respectability. Even today, middle-aged men with older children sometimes adopt an explicitly domestic lifestyle and stick to a vegetarian diet. Most men, however, turn out not to be vegetarians, and although there is an assumption that a vegetarian lifestyle is 'healthier' and helps to control sexual urges, it is fully accepted that men eat meat on a regular basis. For women, on the other hand, meat has always been a less-acceptable treat, and young women in particular are not usually encouraged to consume meat at home. To complicate the discussion even further, the discourse on vegetarianism during the post-Independence period had another distinctive trait, which sits rather uneasily with the commonsense understanding of vegetarianism prevalent among South Asianists. On many festive occasions, including life-cycle rituals, high-caste non-Brahmins, who otherwise have adopted Brahminical cultural traits, serve non-vegetarian feasts-for instance pulao-mangsho (rice with meat) - which used to be the staple for pujas and weddings at which only Brahmins abstained from such non-vegetarian items.

While the link between vegetarianism and caste was vague even in the case of Brahmins, I soon became aware that vegetarianism carries marked ethnic and communal connotations in contemporary Calcutta. Apart from being an indicator of reproductive age/marital status within the Bengali-speaking Hindu community, a discussion of vegetarianism evokes a much broader historical discourse on group-based identities. Vegetarianism is very importantly a marker of religious and ethnic identity and part of the embodied experience of communal relations enacted every day on different levels. Due to the absence of strict vegetarianism among the Brahmins of the region, non-vegetarian diets are not associated so much with caste relations but with the division between Hindus and Muslims on the one hand, and between Bengali Hindu 'sons of the soil' and vegetarian Gujarati and Jain migrants belonging to affluent business communities on the other. Muslims, whose diet is non-vegetarian, are at one end of the spectrum, whilst the North Indian business communities represent the opposite, strictly vegetarian, end, and urban Bengali-speaking Hindus place themselves somewhere in the middle. It is, then, against the definition of these communities as 'other' that Bengali vegetarianism comes into its own. In the words of my interlocutors, Bengali vegetarianism is neither rigid, as in the case of Jains, nor irrelevant, as in the case of Muslims. In either case, the bodies of men belonging to the said group are coded in specific ways - Muslim men being 'more driven by sexual urges', and 'more violent', and Marwari men being 'very controlled'. 
Within this specific multicultural urban context, 'Bengali cuisine' or bangla ranna is envisaged as largely vegetarian. Although it is historically specific and more importantly of relatively recent origin, it is locally interpreted as the main marker of 'traditional' Bengali identity. Cultivated in a very self-conscious way, the everyday meals (described as a 'cuisine') served in middle-class homes are elaborate, labour-intensive and relatively costly. Moreover, they are constitutive of a distinct urban Bengali middle-class domesticity that relies on at least one woman fully devoted to cooking and the availability of servants. In this way, the kind of food consumed helps to maintain specific gender relations, which link women's roles as housewives and mothers to consumption patterns and communal identities produced in the home.

The discussion thus moves away from a notion of vegetarianism as simply prescriptive, and provides us instead with a view of vegetarianism as part of a hegemonic and very bourgeois claim to distinction. Being Bengali Hindu in this stratum of urban society implies a strong emphasis on food knowledge and food consumption in everyday life, and the way the related practices are valued is an (often ironic) but serious marker of a naturalised sense of belonging.

\section{The Nationalist Legacy}

This sense of belonging has not always been so explicitly 'vegetarian', even where Bengali high castes were concerned. During the colonial period, meat played an important part in affluent Calcutta households, including those of wealthy Bengali landlords and businessmen, who indulged an aristocratic preference for non-vegetarian Mogul cuisine. Emulating courtly lifestyles, Hindu households employed Muslim cooks to prepare meat dishes to be consumed by men in the outer parts of the house. With the emergence of a service-oriented middle class - which could not afford most of the customs popular with the colonial aristocracy - and the nationalist movement, other ideals of cultured eating emerged. A new emphasis on 'Bengali' cooking, as opposed to 'Muslim' food, facilitated the development of a 'vegetarian' diet in Bengali homes. Furthermore, building on earlier notions of male celibacy and women's chastity, the alternative masculinity that Bengali elite intellectuals carved out for themselves filtered down into everyday practices so that a new, less 'heating' diet became acceptable even amongst those who could afford nonvegetarian items. Self-control, not the indulgence of the past, became the hallmark of middle-class Bengali lifestyles and the body became a prime site for alternative truths based on self-discipline. As Indira Chowdhury remarks with reference to the reformer Vivekananda, whose writings became hugely popular in these families, 'It was against the western obsession with [sic] body that 
Vivekananda posited the notion of disciplining the body in order to train the spirit and make it truly manly. ${ }^{7}$ With reference to women, self-discipline to produce somatic truths fitted well with earlier regimes, which as Uma Chakravarti points out were based on patrivrata and the submission of women to their husbands - an ideology women not only accepted but internalised as an expression of modern 'selfhood'. ${ }^{8}$ This ideology was transformed and expanded in the course of the nationalist movement and managed to integrate cultural and political nationalism as part of the re-invention of patriarchy within a colonial situation. Crucially this re-invention was based on the control of women's sexuality, the mechanisms of which had to be adjusted to a rapidlychanging environment. What changed women's lives was not so much a new understanding of women's sexuality, but a transformation of their roles and responsibilities both in real life and on an ideological level. As Tanika Sarkar notes with reference to Bengali Hindu wives, the new nationalist regime defined the female body as the opposite of the weak and effeminate male body and this shift suggested new disciplinary practices. Within nationalist discourse the earlier despised female body was

held to be pure and unmarked, loyal, and subservient to the discipline of the shastras alone. It was not a free body by any means, but one ruled by 'our' scriptures, 'our' custom. The difference with the male body bestowed on it a redemptive strength for the community as a whole. ${ }^{9}$

As a 'repository' of power, the new Bengali Hindu woman drew on her 'traditional' ability to endure pain - like the hardships of widowhood or giving birth - for which vegetarianism had became emblematic. But it was not only women who had to be pure for the sake of the nation. From the early days when the leaders of the Bengal renaissance had 'converted' to Western ways by adopting knives and forks at home, the debate about diet had come a long way when writer Bankimchandra Chatterjee became a vegetarian in the late 1880s. Drawing on the pervasive link between 'purity', 'spiritual strength' and the control of female sexuality for male liberation, the nationalist movement venerated female reproductive power and strength (shakti) and this new discourse implicated middle-class women as disciplined subjects per se. As such,

\footnotetext{
${ }^{7}$ See Indira Chowdhury, The Frail Hero and Virile History: Gender and the Politics of Culture in Colonial Bengal (Delhi: Oxford University Press, 1998), p.130.

${ }^{8}$ See Uma Chakravarti, 'Conceptualising Brahmanical Patriarchy in Early India: Gender, Caste, Class and State', in Economic and Political Weekly, (3 April 1993), pp.579-85.

${ }^{9}$ Tanika Sarkar, Hindu Wife, Hindu Nation: Community, Religion, and Cultural Nationalism (London: Hurst, 2001), pp.202-3.
} 
they had to be enabled to control their 'natural' urges by means of domestic ritual centred around fasting, and acculturated to thinking of their traditional commitment to serving husbands and extended family as a service to the wider nation. They also had to see themselves and their autobiographical pasts and futures through the ideal of becoming mothers of virile sons. Furthermore the new ways of being female in 'reformed' Bengali middle-class homes facilitated ideas about the female body which linked various kinds of 'modern' knowledge about education, hygiene and home economics with earlier somatic truths. ${ }^{10}$ Where women's sexuality had been controlled to protect the purity of the lineage by means of early marriage, the later age of marriage necessitated a further and more drastic regulation of women's sexuality. ${ }^{11}$

And with a rise in the marriage age and the advent of new discourses on selfcontrol and women's purity, the question of how to control women's sexuality gained an additional moral dimension. With reference to earlier discourses, Chakravarti points out that

control over female sexuality was almost obsessively applied among high caste women because the danger to the structure of Brahminical patriarchy was great in their case. The reproduction of the hierarchical caste order with its horror of miscegenation subverting the entire edifice necessitated such stringent control. Unlike the lower caste woman the high caste woman did not labour outside the home or participate in primary production. She was regarded solely as a receptacle through which reproduction could take place. ${ }^{12}$

Now, with higher marriage ages, bringing up daughters in the new setting implied that their mothers had to take more responsibility for them. Thus a discourse on women's moral education, privileging wives and mothers as female educators, emerged. This re-working of traditional Brahminical patriarchy fused modern education, medical knowledge, and 'rational'

\footnotetext{
${ }^{10}$ See for details of these processes Judith Walsh, Domesticity in Colonial India: What Women Learned When Men Gave Them Advice (New Delhi: Oxford University Press, 2004).

${ }^{11}$ See Malavika Karlekar, 'Reflections on Kulin Polygamy-Nistarini Debi's Sekeley Katha', in Patricia Uberoi (ed.), Social Reform, Sexuality and the State (New Delhi: Sage, 1996), pp.135-55. Karlekar points out that early marriage did not necessarily imply that parents had transferred the responsibility for a daughter's wrongdoings successfully to a husband, i.e. in the case of kulin Brahmins, whose wives remained in their parental home. But even here the concern was not with the actual sexual activities of women, but with the possibility of illegitimate offspring.

${ }^{12}$ Uma Chakravarti, 'Gender, Caste and Labour: Ideological and Material Structure of Widowhood', in Economic and Political Weekly (9 Sept. 1995), p.2251.
} 
approaches to housekeeping, and was first and foremost located in the home. Here, the new woman was required not only to guard her own conduct, but to guarantee the quality of the offspring she would produce. Increasingly, this implied a commitment to discipline before and after birth. Based on the reconceptualisation of the way gendered bodies and minds were linked, and the place of customary practices in a modern world, this re-working of femininity also implied a re-evaluation of what it meant to be a vegetarian.

\section{Post Independence}

The vignette of dietary regimes in a middle-class, high-caste Bengali Hindu family outlined above is fairly typical of what could be expected in the period between Independence and the moment in the 1990s when economic reforms began to have an impact on the lives of ordinary Calcuttans. With Independence, the importance of Bengali middle-class women's practices, which had been styled as exemplary for the nationalist project as a whole, faded. But in their place, a new discourse on a pan-Indian identity, regulated through the many institutions of the state, brought out the meaning of 'Bengali' domesticity as opposed to 'other' such constructs even more clearly. In a multicultural setting like Calcutta, communal histories and identities are played out not only on the big screen of public lives, but resonate also, and perhaps more so, in domestic practices. Given the importance of commensality, purity and chastity in the past, new roles for the relatively-privileged urban female elites were largely directed towards the home, and supported a strongly classbased model of original 'Bengali' womanhood - one based on the ideal of the chaste housewife and, increasingly, on a model of 'intensive mothering. ${ }^{13}$ While communal tensions, the influx of refugees from East Bengal and the restructuring of the middle classes around the widening government sector all contributed to what has since become the 'Bengali' diet, women's roles and their relationship with food-as processors and nurturers in the Bengali home-were strengthened and have, as I argue below, remained crucial in the post-liberalisation period.

The influx of East Bengali refugees to the city after Partition contributed to an increase in the consumption of specific items such as fish and rice, which are

\footnotetext{
${ }^{13}$ Judith Walsh discusses this ideal in terms of a 'global domesticity' that emerged in the colonial period. See Walsh, Domesticity in Colonial India: What Women Learned When Men Gave Them Advice. I have written elsewhere about the significance of lunchboxes as a site for intensive mothering and the reproduction of ethnic and class-based identities. See Henrike Donner, 'Committed Mothers and Well-Adjusted Children: Privatisation, Early-Years Education and Motherhood in Calcutta Middle-Class Families', in Modern Asian Studies, Vol.40, no.2 (2006), pp.339-64.
} 
today common among the more affluent sections of society. Today, the highlyritualised everyday meal of the middle-class household centering on fish is seen as a hallmark of regional identity. Indeed, with middle-class migration a part of everyday life, this iconic type of Bengali cuisine has supplanted the vernacular as the most important signifier of a globalising Bengali identity. ${ }^{14}$

When I arrived to do fieldwork in 1995, my experiences of learning Bengali and living in Calcutta also involved coming to grips with the practical aspects of food-i.e. where to shop, how to cook and of course how to eat, as well as some knowledge about the propensities of specific items. I soon realised that if I wanted to pursue my interest in kinship and gender in a Bengali-speaking middle-class environment - and in particular if I wanted to talk to women-I not only had to learn Bengali, but also needed to adjust my research to a lifestyle which centres around food and eating.

\section{Post Liberalisation}

At the time of my first extended fieldwork between 1995 and 1997, economic liberalisation had established a firm hold over the economy and culture of the middle classes in Indian cities. Consequently, the lifestyle of the Bengali families I worked with was gradually becoming much more openly-determined by the arrival of new commodities, amongst them pre-processed foods and 'foreign' ingredients. New practices like 'Western' fast food restaurants turned into markers of 'middle class-ness', and the effects of these changes were discussed frequently. Often, while 'globalisation' and 'consumerism' featured ambiguously, new food items and food-related practices were welcomed enthusiastically and quickly adopted. In 1995 when I started my fieldwork in Calcutta, my earlier experiences were still sufficient to set up a household in a thoroughly middle-class neighbourhood: just like everyone else, I purchased fresh ingredients daily from the market, and became annoyed by shortages of specific items including fresh milk, cheese and bread. I cooked most meals from scratch without the use of 'ready-made' spices and semi-processed items; Chinese pasta substitutes remained my main indulgence. Most of the women I came to work with were Bengali-speaking Hindus, and prided themselves on

\footnotetext{
${ }^{14}$ This is evident in the large number of food memoirs produced and marketed for the Bengali diaspora and the importance migrant communities put on keeping their diet 'Bengali'. For a very detailed description of new patterns among middle-class migrants in the US see Krishnendu Ray, The Migrants' Table: Meals and Memories in Bengali American Households (Philadelphia: Temple University Press, 2005). For an annotated cookbook see Chitrita Banerjee, Life and Food in Bengal (London: Penguin, 1991), as well as her memories of growing up in an affluent Bengali middle-class household in her The Hour of the Goddess: Memories of Women, Food and Ritual in Bengal (Calcutta: Seagull, 2001).
} 
the fact that-unlike what they alleged housewives belonging to other communities were doing - they did not use pre-processed foods. Indeed, apart from the ubiquitous Maggi noodles, Nescafe, toasts, jam and Amul milk products, very few obviously ready-made 'Western' ingredients ever entered their kitchens.

But things were changing while I was there: by the middle of 1996, my local neighbourhood stall began to launch special promotions of a wide range of semi-processed items associated with the 'West' which previously had not been available in the locality or had not been in the market at all. As my fieldwork progressed, I saw a huge number of such products come and go. Most disappeared within weeks but several, including a variety of pasta, frozen pizzas, tomato products and frozen chicken products, as well as a wide range of dairy products, were marketed very successfully. All these found their way into the diets of ordinary middle-class families, whose enthusiasm stemmed partly from the fact that such items had previously been the preserve of the seriously rich. Although 'Bengali' food with rice at its centre remained the staple, Western and non-vegetarian items suddenly began to figure on weekly shopping lists, testimony to the transformation taking place in the way middle-class residents ate. But this process also caused debate about the implications of these changes, many of which reached far beyond the mere question of novelty and nutrition, but touched upon other changes in middleclass lifestyles.

An interesting example of the market penetration of such commodities and the transformation of the Bengali diet from a largely vegetarian one towards a largely non-vegetarian one is the success of a local enterprise, Arambhag Limited. This company's name is today synonymous with the above-mentioned transformation of food habits. Starting out as a simple poultry farm, under a franchising system Arambhag began selling frozen chicken parts - an item hitherto unavailable since chickens purchased from the market are always bought whole by the kilo rather than in sections. Whole chickens are fine for cooking Bengali food, but many 'foreign' dishes which the aspiring middle classes here as elsewhere desire require only chicken legs or breasts - so Arambhag products have to be purchased. Furthermore, Arambhag stores are seen as more hygienic than the stalls of the local vendors in the markets, who slaughter their birds in front of their customers. Lastly, these outlets sell other high-status meat products like salami and bacon, which are becoming more and more popular in Bengali-speaking families, and are acceptable as they do not have any 'Muslim' connotations. Thus non-vegetarian dishes, which used to be consumed only in restaurants - including pasta, pizza, and meat dishes - are 
now increasingly prepared and consumed at home. In addition, the consumption of mutton, which has to be purchased from specialist stalls run by Muslims, is also more common than it used to be. However unlike Arambhag chicken (which has almost become the generic term for such nonveg items), mutton is still seen as a typically Muslim item and is therefore not acceptable in most households.

In addition to eating at home, eating out has been transformed as well. Even in the 1990s Calcutta boasted an impressive, very cosmopolitan wealth of eateries, but apart from street-food bought at small stalls, eating out was a rare treat for most of these middle-class families. When they did visit restaurants, they rarely experimented and Mogul or Chinese food was generally the most exotic cuisine they sampled. Today, a range of new up-market eateries has opened in the city and affluent middle-class families now more frequently visit restaurants or order in meals from outside than they did before. Where a family of four such as our neighbours during later stays would previously have restricted their eating out to festive occasions, the same family is now spoilt for choice and may eat out at least twice a month. With a whole range of new restaurants in the city, they can choose between Italian, North Indian, Chinese, vegetarian and the more high-end fusion and 'Western' cuisines.

Another area of change is the food served on special occasions, which up to the mid 1990s was markedly ethnic - that is Bengali-and therefore often vegetarian. Although there has always been a tradition of serving fish and meat as festive food for life-cycle rituals and even pujas, it was not uncommon for feasts prepared by hired cooks for a wedding reception to be entirely 'vegetarian'. These would comprise only bread, rice, vegetables and fish eaten from banana leaves while seated on the roof or in the courtyard of an extended family home. Today Bengali middle-class weddings have become distinctly meat-centred, and although many a mother might publicly bemoan the loss of old-fashioned delicacies freshly prepared by the caterers on the premises and ladled out of a bucket, none that I know would forego the fashionable 'buffetstyle' wedding feast consumed standing up in favour of such a 'traditional' Bengali meal.

These new patterns of food consumption - the availability and popularity of new items and the increased consumption of meat in the home - challenge the way Bengali middle-class residents of Calcutta see themselves and deal with the food world. Clearly a major signifier of changing times, they are also a key marker of inter-generational difference and new consumerist lifestyles that challenge understandings of gendered consumption. Furthermore, young men 
and women have increasing access to a variety of foodstuffs outside the home, while mothers see it as their duty to re-establish control and retain a sense of ethnic identity which is closely linked to 'home-made' meals.

\section{Contemporary Gendered Practices}

In the course of my earlier visit I had come to believe that though most middleclass Bengalis consumed meat outside their own homes in the form of kebabs and Chinese meals, this was largely seen as a 'modern' transgression from a supposedly 'traditional Bengali diet' constructed along the lines of Hindu highcaste preferences. Furthermore, there were significant gendered differences in the way these patterns were played out. Whilst men, who were actively styling themselves as 'modern' through consumption, would be expected to eat at least chicken, and even schoolgirls were sometimes treated to kebabs, married women of reproductive age did not usually express a specific liking for meat dishes. In the same households where meat was allowed and even expected to be a favourite choice among husbands, boys and children, young adolescent women were often encouraged to go for a vegetarian dish and were not usually expected to express a preference for non-vegetarian items. Very clearly married women, especially those with children, fulfilled the role of gatekeepers and symbols of 'true' Bengali culture. ${ }^{15}$ Just as a married Bengali Hindu woman was expected to wear a sari while men, boys and some girls could wear 'Western' clothes, married women it appears were more constrained where meat-eating was concerned. Vegetarianism was a clearly gendered practice, and thus maternal affections would allow even the most strictly vegetarian widow to be lenient with her sons.

During my fieldwork, most of which took place after economic reforms had been introduced, these food sincerities were gradually challenged by new discourses surrounding food and class-based ideas about the family, as well as regional identity. The broad outline of the Bengali Hindu middle-class approach to vegetarianism remained central to the way people spoke about food, but in the more-conservative and often less-affluent households I came to work with, I found that although men were eating meat inside and outside the house and increasingly children expected to be served non-vegetarian items on a regular basis, many married women described themselves as vegetarians.

\footnotetext{
${ }^{15}$ A common complaint among married women is that any food taken outside makes them ill. See Sara Dickey, 'Permeable Homes: Domestic Service, Household Space, and the Vulnerability of Class Boundaries in Urban India', in American Ethnologist, Vol.27, no.2 (2000), pp.462-89.
} 
In the case of widows and unmarried women, self-definitions as vegetarian are not surprising. Neither are sexually active, and therefore often avoid 'heating' food. Moreover, they are also seen as suffering from physical and psychological ailments. ${ }^{16}$ It is significant that in the view of my interlocutors, the balance of the female body did not depend so much on sexual intercourse-although it was seen as psychologically stabilising - as on the wider reproductive processes it forms part of, including conception and birth. Birthing is seen not just as an important rite of passage, but also as a physical process by which blood - which is produced from food consumed-is turned into the foetal body. Thus menstruation and birthing are said to keep a woman's body balanced and healthy. ${ }^{17}$ While it was not suggested that unmarried women should be forced to become vegetarians (and unlike widows there was no rule that applied to all unmarried women), all those I met were expected to give up eating fish and meat, both regarded not only as 'heating' but also as blood-producing. Since unmarried women are not likely to give birth, even if they may have intercourse, it was assumed that the resulting build-up of blood causes unmarried and premenopausal women to suffer from extremely heavy periods and, following that, anaemia, mood swings and depression.

But significantly, unmarried women who were expected to refrain from sexual intercourse because their bodies might otherwise become unbalanced were not the only female vegetarians in these households. I was told by many middleaged married women that they abstained from eating meat and fish, and followed a vegetarian diet. This vegetarianism among married women of reproductive age was not a convention, but was described by some of them as 'new'. Women I spoke to who had become vegetarians explained their decision as a matter of personal choice - but that choice seems to have been built on either notions of health and fertility or on ideas about chastity. Moreover they represented their decision as a difficult one, because in a context where married women live with their in-laws and prepare meals for the whole extended family, to become a vegetarian was to invite criticism from other family members. In this strata of society marriages are arranged with the 'culture' of both parties in mind, and few non-vegetarian families would choose to accept a vegetarian daughter-in-law in their midst. On the contrary, young married women who become vegetarians are often portrayed by their mothers-in-law as 'difficult'

\footnotetext{
${ }^{16}$ This is also reflected in public discourse on marriage, see for instance Patricia Uberoi, 'When is a Marriage not a Marriage: Sex, Sacrament and Contract in Hindu Marriages', in Patricia Uberoi (ed.), Social Reform, Sexuality and the State (New Delhi: Sage, 1996), p.342.

${ }^{17}$ For a further exploration of these physical processes see Henrike Donner, 'The Place of Birth: Childbearing and Kinship in Calcutta Middle-Class Families', in Medical Anthropology, Vol.22, no.4 (Oct.-Dec. 2003), pp. $303-41$.
} 
and overtly individualistic, and their dietary habits are seen as disruptive and a clear sign of a rebellious character.

It is also significant to note that while a small minority of married women had always adopted vegetarianism for religious reasons, the spread of vegetarianism among middle-class mothers in their thirties and forties is a different phenomenon. It can be interpreted, on the one hand, as part of the gradual integration of medicalised views of reproduction linking good health and fertility to certain diets and, on the other, as an expression of the embedded belief that mothers are the guardians of tradition and bear a duty to regulate new consumption patterns. Furthermore, younger new vegetarians themselves acknowledged that adopting vegetarianism constituted an individualistic gesture in a context in which women share food-related activities and commensality within a joint family setting. Moreover, while many women presented their abstinence from more-expensive and arguably tastier nonvegetarian dishes as a sacrifice, withdrawal from common meals was usually deliberate in the case of daughters-in-law.

Like the ritual fasts (bratas) which form part of these middle-class lifestyles and have featured prominently in the education of housewives from the nineteenth century onwards, in some instances new vegetarianism was understood as a personal choice - though like bratas one informed by a concern for other family members. Fasting on behalf of others was, and is, a woman's issue: on the one hand the duty of a wife and mother, but on the other a personal symbol that allows women to create some individual space in a strictly patrilocal setting. But fasting is also directly related to notions of fertility and reproductive agency. Insofar as fertility and reproduction are concerned, fasting and voluntary vegetarianism support the social role of the maternal body. Among the women I worked with, fasting was common and, like vegetarianism, was said to signify a woman's need for self-control as well as healthy restraint which, it was believed, was particularly important in the case of over-indulgent middle-class Bengali women. In their view, the need for restraint and discipline appears to be even more pressing these days when it is said that consumption has 'gone mad' and the values of the family, as exemplified in the everyday meal, are under threat. But apart from the obvious similarities between vegetarianism and fasting - as practices of corporal control and the domestication of desire, a discourse so brilliantly employed by Mahatma Gandhi - the women pointed out that fasting is not the same as becoming a vegetarian. In their view, fasting has 'always' formed part of women's domestic practices and, as such, is not regarded as disruptive for the family - in contrast to vegetarianism which is not considered part of the repertoire of a dutiful daughter-in-law or wife. 
Thus, far from being a matter of self-realisation in a straightforward individualist sense, the young mothers themselves saw their new regime in a wider context of traditional and modern ideas about fertility, and it turned out that many who had given up meat and fish were part of a married couple that had experienced problems conceiving a child. Moon-Moon, the mother of a six-year-old, pointed out that they had tried for a child for a couple of years during which time she had been to see many doctors, but was assured that nothing was wrong with her. Not a very religious woman in her youth, she had married into a devout family and was lauded for taking up different fasts once the problem had been recognised by the wider family. But when she later on decided to become a vegetarian - a process that became manifest over a period of time-her mother-in-law as well as her sisters-in-law, with whom she shared the daily chores, were not supportive and challenged her decision on numerous occasions. Since the birth of her daughter, she has moved into her own small flat within the bigger residence occupied by her affinal family, and has stopped cooking non-vegetarian food altogether-but rather employs a servant who prepares fish for her husband and daughter.

Like Moon-Moon, in many cases newly-converted vegetarians experienced problems conceiving. These women had usually observed bratas, made offerings to deities, and sought indigenous and allopathic treatments before they changed their diet. In many instances regular fasts and a vegetarian diet had been suggested by a doctor. Meat and fish, which are held responsible for a 'hot' body, were believed by the women to have caused their infertility. Once these wives and future mothers had become vegetarians, their bodies were said to be balanced-so they had a better chance of conceiving.

But this straightforward medical reasoning for new vegetarianism as a way to improve fertility does not explain why, even after having a child, some middle-class mothers feel obliged to remain vegetarians or take up a vegetarian diet after birth. Could it be that vegetarianism is not only a way to enhance women's fertility, but has other beneficial effects too? Explaining why she remained a vegetarian after the birth of her daughter, Moon-Moon, then the proud mother of a five-year-old girl, told me:

I had problems conceiving and first changed my diet, after some time I became a vegetarian and for whatever reason we had a daughter after eight years of marriage, maybe because of the vegetarian food, maybe because of the fasts, maybe because of the 
pilgrimages. I stuck to it because we can't afford to have any more children, living in a tiny flat and so on, and so I try to control myself, and even my husband has become a vegetarian for that reason.

Others, who had not experienced problems conceiving, echoed these comments. Once the desired single-child family is in place, especially if the child is a boy, women are at pains to maintain the status quo - and so they try to abstain from sex. Thus, in the interest of the small family unit and the wider household, they choose vegetarianism as a lifestyle for themselves. In these cases vegetarianism served the double purpose of signalling that the reproductive phase of their lives was over after the birth of a child, and helping them to manage their own sexual desire.

This link between vegetarianism and chastity is, of course, a familiar theme in the lives of devotees and widows (as well as Gandhi's thought) but until recently has had no place in the lives of married women as mothers, who were expected to have numerous children and be sexually active until menopause. Furthermore, while the same women frequently use highly-interventionist contraceptive methods like sterilisation and hysterectomy, the earlier political discourse that links self-control and the moral superiority of a celibate lifestyle is re-appropriated and employed to produce an ideal middle-class family. Currently, middle-class incomes in Calcutta are insufficient, at least in the view of my interlocutors, to allow couples to have more than one child. Like others, Moon-Moon, whose husband is a well-paid sales manager in a private firm, therefore interprets her vegetarianism not only as a sign of devotion to her family, but more importantly as a practice that allows her to provide for her daughter:

Nowadays, with all the stuff you need, you cannot afford to have more than one child - in fact, if you want to give them all they want and need, you can not afford that with the middle-class salary. They need a lot of things to be a success, a lot of money goes into schooling and so on, that is why we have to be careful, you know, that is why we cannot have more children.

Indeed, a number of mothers told me that they had chosen sterilisation at the time of their (Caesarean) birth to avoid further pregnancies for the same reason, and saw their own vegetarianism as part of a strategy to achieve the perfect nuclear family lifestyle. Clearly, a discourse of maternal sacrifice and restraint embodied in vegetarian practice was here providing a language for this 
desire to achieve the perfect family: a language which avoided the less-accepted display of women's use of contraceptives. Mothers more than once mentioned that a consumerist lifestyle and the need for upward mobility did not allow for unrestricted fertility, and women as well as men emphasised the moral/physical benefits of a balanced body. As one mother put it:

When you had one [child], you do not want any more, so you have to stop having sex, and that may be a good thing because you become calmer, you can care better for your family and with only one to look after, you can actually give them every attention. Mind you, it is very exhausting to bring them up nowadays, and so you need to be healthy and alert, not like our mothers, who were so worn out because of all those pregnancies.

Increasingly, such re-interpretations of feminine ideals are directly related to the influx of new consumer goods, and changing dietary patterns more generally which, again, are highly gender-specific. I would like to suggest therefore that the analysis of gendered vegetarianisms opens up a wider field of transformative patterns of gendered consumption in the middle-class 'home'.

\section{Changing Diets: Mothers and Their Children}

Since I started fieldwork in the 1990s some of the most pertinent changes in society have taken place in children's lives. Many of these transformations are related to food consumption. Among the more subtle ones is a tendency among young boys and adolescents to prefer non-vegetarian meals over the 'traditional' vegetarian fare.

I encountered this trend for the first time in 1995 in the house of my Bengali teacher, Mrs. Ghosh, who was married and had two adolescent sons. I noticed that whenever I came for my lessons around 10 am her husband, a retired government employee, left their apartment in South Calcutta carrying the typical nylon shopping-bag middle-class men all over Calcutta use for the purpose. I assumed he was off to the nearby bazaar. But after several weeks I became aware that it took him two hours to return. When I asked my teacher about this, she explained that in addition to doing the usual round at the local bazaar, where he purchased vegetables, fish and groceries, he travelled by tram to a predominantly-Muslim area to buy mutton and chicken for their younger son. It turned out that this boy of fourteen refused to share the fish curries eaten by his parents and older brother, but instead insisted on having mutton or chicken dishes cooked specifically for him. 
Over the years I have come across the same preference for meat, and more specifically red meat, in many young boys from more-affluent Bengali Hindu families, and although many mothers and grandmothers still refuse to prepare mutton in their kitchens, chicken has become a regular item in many middleclass homes. Mothers explained that this was a result of 'youth' culture, into which their sons and daughters had been drawn by TV advertisements. However it seemed to me that the catalyst for change was not so much the advertisements, but the new approach of middle-class families to eating out and their consumption of 'other' food items and preparations classified as nonBengali. With mothers cooking for about three hours anyway, some of the women I interviewed about their children's food habits argued that they had to take it upon themselves to re-create the desired restaurant foods at home. And some would go so far as to cook red meat for their sons - although where the mother of the boy is not the most senior woman and an elderly grandmother is still present, mutton may still be banned out of respect for the 'old ways'.

But the gendered character of this increasing preference for red meat among boys is even more pronounced: whilst some young boys can insist on red meat at home, a daughter's love of kebabs will not move her mother or grandmother to serve them. At the same time, while girls in Bengali middle-class families are equally encouraged to develop very specific tastes (indulged by mothers and grandmothers alike), girls are less likely than boys to succeed when they ask for non-vegetarian dishes and are therefore provided with such special items much less frequently. Furthermore, girls' food intake outside the home is much more strictly controlled - for example a liking for street food such as 'Chinese' chow min noodles or phuchka (lentil balls filled with potato mix and tamarind sauce) is seen as an unhealthy but permissible treat for boys but as transgressive behaviour in the case of girls. ${ }^{18}$

The diet of school-going children and students has, of course, always been a matter of concern for Bengali mothers. The readily-available street food and snacks from 'outside' are regarded as dangerous and polluted because of their association with lower-class producers and the real hygiene issues associated with their preparation. ${ }^{19}$ Thus the mothers I spoke to try to provide their children with 'good' tasty food at home - even if these are meat-based dishes, or variations on the snacks offered by street vendors. Most mothers agreed that while daughters

\footnotetext{
${ }^{18}$ The street food available in Calcutta carries multicultural connotations, especially local specialities like chow min noodles, invented by its Chinese community, or the mouthwatering phuchka balls, a variation on North Indian pani puri.

${ }^{19}$ See Bhaskar Mukhopadhyay, 'Between Elite Hysteria and Subaltern Carnivalesque: The Politics of StreetFood in the City of Calcutta', in South Asia Research, Vol.24, no.1 (2004), pp.37-50.
} 
should not be encouraged to consume too much meat, a son's preference for meat is accepted because of the 'virile' connotations meat carries. And many households with younger children appear to have incorporated some nonBengali foods, such as pasta, into the weekly food plan. All-time non-Bengali favourites among children and adolescents I met included Chinese dishes, rich North Indian preparations, and 'Western' items, all of which mothers try to represent as snacks (jholkabar) rather than full 'Bengali' meals. The preference for non-Bengali food is generally seen as unhealthy, either because it contains meat, or is regarded as too spicy and 'oily'; young people are expected to at least accept a Bengali diet, if not to like it more. The young, in return, are keen on eating out and have embraced a contemporary lifestyle which allows them to appear as 'modern'. The tension between these two desiderata is much more marked in the case of girls. This has escaped the notice of many commentators, but not of the locals. ${ }^{20}$ Madushree, the mother of an adolescent girl, explained:

Nowadays they get all these foods in the restaurants and coffee shops, and because I don't want her to eat anything there I told her: 'Let me know what it is you want and I will cook it for you', so I am doing chow min and kebabs as well as pasta for her here at home. Some of the ingredients like tinned tuna and sweet corn are expensive but it is better than eating the same food outside, she would just fall ill.

The same sentiment was echoed in the comments of Shreya's mother, who herself had become a vegetarian before the birth of her daughter:

Whatever she wants she gets, whether she has seen it on TV or just heard about it from someone, but I make sure that everything she eats is cooked in the home and never allow her to eat outside-I don't even take her to weddings or the club to avoid her eating anything prepared elsewhere. She is very weak and she would only fall ill if she had outside food, so I cook pasta and other special dishes for her here at home, at least she can have them here.

Controlled by mothers and grandmothers, this kind of food is perfectly acceptable for home consumption and, played right, a son or daughter can manipulate the competition between the women in the house to receive regular servings of these special new dishes. Just as the intra-household dynamics of food preparation and consumption may lead young mothers to assert their

${ }^{20} \mathrm{Ibid}$. 
individuality by becoming vegetarians, the same women are often keen to produce special dishes for children who, in turn, may refuse the commensality of food cooked for all family members and demand special treats on a regular basis.

A pronounced dislike of fish is a common symbol for this new power dynamic, since fish represents the ultimate symbol of Bengali cuisine. This was the case with Anuradha, the sixteen-year-old second of three cousins living in a joint family, whose abstinence from fish stemmed, according to her mother (herself a vegetarian of the younger generation), from competition with her elder cousin, the intelligent and well-turned-out daughter of her paternal uncle. To the utter disgust of her aunt, who was the main cook in the house, Anuradha refused to eat any fish. Moreover, although she often suffered from 'gastric' problems after eating outside, she avoided family meals altogether. Female eating habits in this family had been largely vegetarian, with all three adult women (Anuradha's mother, older aunt and widowed grandmother) not eating fish for various reasons: the elderly grandmother since she became a widow; the aunt after she decided that it was too late for her to try for a son once her daughter had reached the age of twelve; and her mother after she had given birth to a much-adored son when Anuradha was six. Choosing her own diet could be interpreted as the practice of a young adult woman imitating her older female relatives, were it not for the fact that Anuradha's diet was not marked by restraint but, as her aunt pointed out, fitted with her general admiration for a consumerist lifestyle. With her refusal to eat fish went a preference for meatbased 'Mogul' dishes and Western clothes. She refused to wear anything considered 'traditional' just as she shunned a traditional diet. Here is another example of a female member of a joint family turning her own dietary preferences into an individualist gesture. But unlike the mother, who has become a dutiful vegetarian daughter-in-law, the daughter indulged herself, exploiting the freedom provided by her natal home.

\section{Conclusion}

Is the 'new vegetarianism' an affirmative gesture of relatively-privileged middleclass mothers who adjust to the demands of new consumption patterns by simply re-appropriating a traditional practice, a re-alignment of sorts, or do women's practices related to food represent a certain space for female agency within a rigidly-structured family setting?

In this article I have charted the terrain of new food-related practices in relation to gender-based identities among the urban middle classes in Calcutta. It is clear that, with reference to the vegetarian/non-vegetarian divide, the group-based 
differences and therefore the direct transactional meanings of food - for instance manifest in commensality between castes and ethnic groups at work and in public places - have become narrower. Among the Bengali Hindu middle class, vegetarianism is no longer perceived simply as a trait of the family or wider kin group, but is now very strongly associated with personal choices. Thus, vegetarianism today is not so much based on the needs of society and the family to control women's sexuality (as was the case in the nineteenth-century discourse on widowhood), but on ideas about the need to retain the ideal of the chaste wife and become a suitable mother in a modernising and thus increasingly-challenging setting. Although I agree with Alter, who asserts that 'female chastity does not seem to be constructed in terms of a bio-moral truth along the same lines as male celibacy', ${ }^{21}$ I would like to suggest that female vegetarianism and the chastity it supports indicate rather a different kind of truth. Vegetarianism is one way of adjusting the need for bio-moral truth through gendered personhood in changing times, and thus is re-invented. Where previously vegetarianism was for widows, today young married women need to turn into vegetarians; where earlier, fertility proven through the procreation of many children essentially established womanhood and the self, today the female body has to be seen in public as a site of restraint - not for a higher political aim, as Gandhi envisaged, but to produce the ideal middle-class single-child family. Exemplified in dietary restrictions, which are part of a wider need for self-discipline, such body cultures are no longer directed at the discourse of the nation, but at the much-narrower middle-class ideal of the nuclear household.

No doubt, the personal symbolism of mothers' vegetarianism also represents a means to be individualistic in a more and more consumption-orientated environment. And it certainly emphasises the importance of choice and individual agency in a highly-visible way. By adopting the garb of a chaste wife, and taking on ascetic practices, often in a very self-conscious manner, younger married women who feel that their husband's families control their lives can carve out a niche for themselves. Using the ideology of the single-child family and the cultural repertoire of maternal devotion (fasts on behalf of others and politicised ascetic vegetarianism), these young women are able to take a stance and create a space where their individuality has to be recognised by their affines. This somatic truth is political insofar as it re-constitutes a gendered morality at a time when consumerist indulgence establishes a tight grip over middle-class imaginations. Acting purposefully on the body through corporal regimes that include 'traditional' practices like fasts and vegetarianism, these young mothers re-establish the maternal body as a site for 'true' Bengali culture.

${ }^{21}$ Alter, 'Seminal Truth: A Modern Science of Male Celibacy in North India', p.278. 
Such a feminist reading of the material is helpful because it directs our attention away from the two conventional frameworks through which female vegetarianism has been interpreted, and which are particularly dear to anthropologists: firstly the construct that holds that the control of sexual urges and women's sexuality in particular can be interpreted within a straightforward scheme of 'traditional' versus 'modern' practices; and secondly the construct that sees the link between vegetarianism and sexuality in the modern urban setting as one solely grounded in psychological models of embodiment. Neither of those explanations, which locate resistance in discourses bridging gender and sexuality within a patriarchal framework, and as embodied in practices of self-discipline, are useful to analyse the potential of these kinds of agency for women. As Saba Mahmood has rightly pointed out with reference to women in the Egyptian mosque movement, we need to pay more attention to other modalities of agency, and raise 'questions that remain submerged ... if agency is analyzed in terms of resistance to the subordinating function of power'. ${ }^{22}$ Mahmood reminds us that this is as much an analytical question as it is a political one, and thus argues with reference to the piety movement that any analysis of transformation

must begin with an analysis of the specific practices of subjectivitation that make the subjects of a particular social imaginery possible... this means closely analysizing the scaffolding of practices - both argumentative and embodied - that secured the mosque participants' attachment to patriarchal forms of life that, in turn, provided the necessary conditions for both their subordination and their agency. ${ }^{23}$

But as Ann Anagnost points out, the rhetoric of self-development, of teaching, learning and disciplining, bears in itself a resemblance with neo-liberal ideologies. She observes that the transformations that reproductive processes and thus the idea of the maternal body are undergoing in urban China are ambivalent - which is an insight equally relevant in the context of urban India, or indeed to the life of middle classes everywhere. It reminds us that the modalities of agency located in discourses around the maternal body are determined by the wider socio-economic context, and that the contemporary politics of reproduction are as much about potential transformations and selfrealisation as they are about exploitation:

\footnotetext{
${ }^{22}$ Saba Mahmood, Politics of Piety: The Islamic Revival and the Feminist Subject (Princeton: Princeton University Press, 2005), p.154.

${ }^{23}$ Ibid.
} 
The latent capacities of the human body are expressible in a rhetoric of development. It is self-development that 'qualifies' neoliberal subjects, so that the actualization of the body's latent potentialities becomes an expression of value. Viewed positively, this self-development may be seen as the actualization of human possibility - the achievement of a telos of creativity that achieves its fullest expression. However, in a more critical light, we might also recognize this development as opening the body to a regime of exploitation perhaps unparalleled in human history. ${ }^{24}$

\section{Bibliography}

Alter, Joseph S., 'Seminal Truth: A Modern Science of Male Celibacy in North India', in Medical Anthropological Quarterly, Vol.11, no.3 (1997), pp.275-98.

Anagnost, Ann, 'The Corporal Politics of Quality (Suzhi)', in Public Culture, Vol.16, no.2 (2004), pp.189-208.

Banerjee, Chitrita, Life and Food in Bengal (London: Penguin, 1991).

Banerjee, Chitrita, The Hour of the Goddess: Memories of Women, Food and Ritual in Bengal (Calcutta: Seagull, 2001).

Caplan, Pat, 'Food in Middle-Class Madras Households from the 1970s to 1990s', in Katarzyna Cwiertka and Boudewijn C.A. Walraven (eds), Asian Food: The Global and the Local (Richmond: Curzon, 2002), pp.46-62.

Chakravarti, Uma, 'Conceptualising Brahmanical Patriarchy in Early India: Gender, Caste, Class and State', in Economic and Political Weekly (3 April 1993), pp.579-85.

Chakravarti, Uma, 'Gender, Caste and Labour: Ideological and Material Structure of Widowhood', in Economic and Political Weekly (9 Sept. 1995), pp.2248-56.

Chowdhury, Indira, The Frail Hero and Virile History: Gender and the Politics of Culture in Colonial Bengal (Delhi: Oxford University Press, 1998).

Conlon, Frank F., 'Dining Out in Bombay', in Carol A. Breckenridge (ed.), Consuming Modernity: Public Culture in a South Asian World (Minneapolis: University of Minnesota Press, 1995), pp.90-127.

Dickey, Sara, 'Permeable Homes: Domestic Service, Household Space, and the Vulnerability of Class Boundaries in Urban India', in American Ethnologist, Vol.27, no.2 (2000), pp.462-89.

Donner, Henrike, 'The Place of Birth: Childbearing and Kinship in Calcutta MiddleClass Families', in Medical Anthropology, Vol.22, no.4 (Oct. - Dec. 2003), pp.303 - 41.

Donner, Henrike, 'Committed Mothers and Well-Adjusted Children: Privatisation, Early-Years Education and Motherhood in Calcutta Middle-Class Families', in Modern Asian Studies, Vol.40, no.2 (2006), pp.339-64.

Jing, Jun (ed.), Feeding China's Little Emperors: Food, Children and Social Change (Stanford: Stanford University Press, 2000).

\footnotetext{
${ }^{24}$ Ann Anagnost, 'The Corporal Politics of Quality (Suzhi)' in Public Culture, Vol.16, no.2, (2004), p.201.
} 
Karlekar, Malavika, 'Reflections on Kulin Polygamy-Nistarini Debi's Sekeley Katha', in Patricia Uberoi (ed.), Social Reform, Sexuality and the State (New Delhi: Sage, 1996), pp.135-55.

Liechty, Mark, Suitably Modern: Making Middle-Class Culture in a New Consumer Society (Princeton: Princeton University Press, 2003).

Mahmood, Saba, Politics of Piety: The Islamic Revival and the Feminist Subject (Princeton: Princeton University Press, 2005).

Mazzarella, William, Shovelling Smoke: Advertising and Globalization in Contemporary India (Durham: Duke University Press, 2003).

Mukhopadhyay, Bhaskar, 'Between Elite Hysteria and Subaltern Carnivalesque: The Politics of Street-Food in the City of Calcutta', in South Asia Research, Vol.24, no.1 (2004), pp.37-50.

Nair, Rukmini Bhair, 'Are We What We Eat?', in Seminar, No.545 (Jan. 2005) [http:// www.india-seminar.com/semframe.html].

Ray, Krishnendu, The Migrants Table: Meals and Memories in Bengali American Households (Philadelphia: Temple University Press, 2005).

Sarkar, Tanika, Hindu Wife, Hindu Nation: Community, Religion, and Cultural Nationalism (London: Hurst, 2001).

Uberoi, Patricia, 'When is a Marriage Not a Marriage: Sex, Sacrament and Contract in Hindu Marriages', in Patricia Uberoi (ed.), Social Reform, Sexuality and the State (New Delhi: Sage, 1996), pp.319-46.

Walsh, Judith, Domesticity in Colonial India: What Women Learned When Men Gave Them Advice (New Delhi: Oxford University Press, 2004). 